\title{
Case Study: Eco-Jet Airlines
}

Rajen K. Tibrewala, New York Institute of Technology, USA

\begin{abstract}
Typical student learning objectives in an Operations Management course are to demonstrate comprehensive knowledge of the concepts and to use technology for solving frequently occurring problems. Eco-Jet Airlines case has been designed to be used as an assessment tool by the instructor, teaching a senior level undergraduate or a first level graduate course. It starts with an interesting story line and presents the tasks to the student in an interview format. Several small projects typically appearing in a business environment are assigned to the student during the discussion. To complete the case study successfully, the students must use analytical techniques and the software included with popular Operations Management textbooks. Finally, students are asked to prepare an internal memo with specific deliverables.
\end{abstract}

Keywords: Comprehensive Business Case, Operations Case study, Control Charts, Complex CPM Problem, Shift Scheduling, Cyclical Staffing

\section{INTRODUCTION}

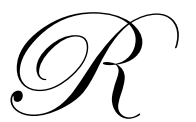

ay Tanaka has been working for Eco-Jet, a regional air line, for the last six years. Ray started as a ticket agent in the customer check-in area, and has held several other positions at various airports. $\mathrm{He}$ is presently working as a senior customer service associate at Newark airport. He is a keen observer and has a good track record as an employee of Eco-Jet.

In addition to working for Eco-Jet, Ray has been taking on-line MBA courses. Ray found the Operations Management course to be most informative and enjoyable. He has just completed the MBA program, and he is interested in being transferred to a more responsible position commensurate with his education and experience. Ray expressed his interest to David Malone, the human resource manager of Eco-Jet.

Deregulation of airlines has had a devastating effect on the bottom line of many major carriers. Many national and international airlines have declared bankruptcy and are in the process of curtailing services. However, Eco-Jet is a low cost regional carrier that has been experiencing a dramatic growth during the same time period. At the present time, Eco-Jet operates more than 700 flights every day within the northeastern part of the country.

Patricia Dolan is the vice-president of airline operations at Eco-Jet. She is well regarded as a senior executive in the firm, and is known for running effective and efficient operations. She has an MBA from The Kelley School of Business with a concentration in operations management. Patricia would love to use various tools available to operations managers, but she does not have the time to do the detailed work on her own.

During a management meeting, David Malone was talking to Patricia Dolan and he mentioned Ray's interest in the operations area. Patricia was not quite sure whether Ray can handle sophisticated analytical work required in the operations area. However, she agreed to meet with Ray for an interview. Following are some excerpts from the interview.

Patricia: I am impressed with your diligence in pursuing an MBA program, while working all kinds of hours for Eco-Jet.

Ray: I would not have been able to complete this program in a conventional school, but the online format gave me the flexibility to work from home at any time of the day. 
Patricia: David was telling me that you have a lot of interest in the operations area. Do you feel comfortable in using various techniques such as PERT/CPM and statistical control charts?

Ray: We used these techniques throughout the course to work on several case studies. My term project involved the use of software to solve several real life problems.

Patricia: You have been at Eco-Jet long enough to know that we run a very tight ship and we cannot afford to add unnecessarily to the overhead. I have often thought about hiring someone to help me with all different technical tasks, however, I do not have time to train a new person about operations. You have the knowledge of our operations and I would not need to spend too much time in giving you directions. Right!!

Ray: Sure!! I am a quick learner. Just tell me what needs to be done and I will get it done.

Patricia: Okay. Let us give it a try. I have several action items which need to be taken care of in a week. As you know that we are adding more flights in Newark, and we need to refurbish the passenger waiting area at the new gates. I have selected three acceptable vendors and my assistant Sarah has prepared a summary of the proposals. I have not had time to evaluate these three proposals. Could you please do a quick evaluation for me?

\section{Appendix 1 - Vendor Cost Data}

Ray: Do we need to look at other factors aside from costs to select among these vendors?

Patricia: No, we just want to look at the costs. All three are reputable and responsive vendors. Sarah's summary also has our forecast for the number of passengers to be handled at these gates.

\section{Appendix 2 - Passenger Forecast Data}

The second thing I would like you to do is to develop a project management plan for completing the new gate areas. Based on our prior experience with such projects, we have developed a work breakdown structure. Sarah has a copy of it. What are our chances of getting the whole job done in about two months?

\section{Appendix 3 - Work Breakdown Structure}

Ray: I will use a CPM technique to develop the project plan.

Patricia: That sounds great. We will be using the new gates starting from 6 AM to 10 PM every day of the week. As you know, all our employees work in of the two shifts: morning shift from 6 AM to 2 PM and the afternoon shift from 2 PM to 10 PM. I need to tell David about the number of new customer service people we need to hire for the additional gates. I promised to get back to him in a week.

Ray: From the passenger forecast, I can use our regular rule of one agent for every hundred passengers. I will also make sure that every employee gets two consecutive days off. I will also add the usual $10 \%$ additional staff to cover vacations, sick-days, and absenteeism.

Patricia: You seem to be a quick learner and your knowledge of our operations is a definite plus. One last thing which you may be able to help me with this week is responding to Paul, our V.P. of communications, about delays in our flights. Typically, in our industry, three to fifteen percent of the flights are late. Paul wanted to know how we are doing compared to the industry. I had asked flight operations to send the sample data about flight delays.

\section{Appendix 4 - Flight Delay Data}

Ray: I believe I can make conclusions from this data and prepare a response for Paul for your approval.

Patricia: Ray, do you think you can do these tasks for me in a week? 
Ray: I am fairly confident that I could do these four tasks in a week.

Patricia: Look Ray, I cannot promise anything but think of this week as a trial period. Give a memo summarizing what you have done by the end of the week. If you find this kind of work interesting and you can take over these types of tasks from me, I would ask my boss to create an operations manager position. If it does not work out, your current position is still there for you.

Ray: Okay. You can count on me. I will have it done for you.

Assume that you are Ray and your job during the week is to work on the four tasks assigned to you by Patricia and prepare a summary memo to describe what you have done.

\section{Project Deliverables and Guidelines}

There are five deliverables (each determining $20 \%$ of the grade) in this project. Since this is your first project a breakdown of the deliverables and some guide lines are specified below. Please remember, that in real life situations you would not be given guide lines.

\section{Deliverable \# 1:}

Prepare a memo to send to Patricia which provides a one page summary of what you have done. The first paragraph should be general comments relating to your experience over the week. Other four paragraphs should summarize your conclusions about each of the four tasks. Attach four exhibits showing your detailed work.

\section{Deliverable \# 2:}

Exhibit 1 - Vendor Cost Comparison

Examine the passenger forecast to calculate peak number of passengers handled each day and select the least expensive vendor.

\section{Deliverable \# 3:}

Exhibit 2 - Project Management

Use Project Management module of Excel-OM to find the critical path and the required probability of completion.

\section{Deliverable \# 4:}

\section{Exhibit 3 - Employee Requirements}

Convert passenger forecasts into gate agent requirements in each shift for each day of the week and then find the total number of employees to be hired for each shift.

\section{Deliverable \# 5:}

Exhibit 4 - Flight Delay Analysis

Prepare a p-chart to see if the proportion flight delays are under control. Make conclusions from the control chart about the stability of the process and compare to Eco-Jet control limits and industry standards.

Submit the memo and the exhibits to the instructor for grading.

\section{AUTHOR INFORMATION}

Dr. Rajen Tibrewala is currently a Professor of Quantitative Methods at New York Institute of Technology. He received his doctorate in Operations Research from Columbia University. He has been consultant to more than 70 corporations in planning and implementing productivity improvement projects. His research interests include data mining, information systems planning, and supply chain management. 


\section{APPENDIX 1: VENDOR COST DATA}

\section{Summary of Costs (Prepared by Accounting)}

After several meetings with vendors, the fixed cost and the variable cost proposed by each of the three vendors have been finalized. The results are shown in the table below.

\begin{tabular}{|c|c|c|}
\hline & Fixed Costs & Variable Costs \\
\hline American Airport Construction, Inc. & $\$ 800,000$ & $\$ 1500$ \\
\hline National Airport Contracting Corp. & $\$ 900,000$ & $\$ 1200$ \\
\hline Newark Airport Construction Corp & $\$ 700,000$ & $\$ 1800$ \\
\hline
\end{tabular}

\section{$\underline{\text { Notes }}$}

1. The fixed costs for each vendor include all flooring, wall paneling, ceiling, electrical, telecom wiring, and plumbing work.

2. The tasks to be performed by each vendor and the time estimates for completing each tasks have been finalized. In order to permit an Apple to Apple comparison of costs, all three vendors were asked to use the same time estimates.

3. Eco-Jet will need to supply the final plans for wiring, electrical work, network jacks, and plumbing plans.

4. Eco-Jet will also be responsible for acquisition of chairs, tables, ticket counters, fixtures, and other furniture. The vendor will be responsible for all installation.

5. All three vendors have worked with Eco-Jet before and there is no significant difference between dependability and quality of vendors.

6. The total variable costs will depend upon the peak hour design capacity of the gate area expressed in terms of the maximum number of passenger departures per hour.

It is important to note that in real life situation, a significant amount of effort is required in collecting the data by examining various documents and interviewing different people, developing assumptions to simplify the analysis, and presenting the data in an understandable form.

\section{APPENDIX 2 - PASSENGER FORECAST DATA}

\section{Passenger Forecasts for the New Gate Area at Newark} (To be used for facility and manpower planning)

\begin{tabular}{|l|c|c|c|c|c|c|c|}
\hline \multicolumn{1}{|c|}{ Description } & Mon & Tue & Wed & Thu & Fri & Sat & Sun \\
\hline Total between 6 AM and 2 PM & 800 & 600 & 500 & 600 & 700 & 200 & 400 \\
\hline Total between 2 PM and 10 PM & 700 & 400 & 500 & 700 & 900 & 300 & 700 \\
\hline Peak hour Traffic & 175 & 150 & 150 & 150 & 200 & 100 & 175 \\
\hline & & & & & & & \\
\hline
\end{tabular}

\section{$\underline{\text { Notes }}$}

1. The passenger forecasts for all flights departing Newark in the morning and the evening shifts has been combined together to show daily total load in each shift. The results have been rounded to the nearest one hundred.

2. Use peak hour traffic to design the passenger check-in area at the gates. The seating area should have enough capacity to accommodate the peak number of passengers. 
3. The number of Eco-Jet agents (customer service personnel) in the newly built gate area will depend upon the total traffic during the eight hour shift.

4. The current rule of using one customer service personnel to handle one hundred departures during an eight hour shift seems to be working well. There is plenty of slack time built into these estimates for coffee and lunch breaks.

It is important to note that in real life situation, a significant amount of effort is required in collecting the data by examining various documents and interviewing different people, developing assumptions to simplify the analysis, and presenting the data in an understandable form.

\section{APPENDIX 3 - WORK BREAKDOWN STRUCTURE}

\section{Major Tasks and Completion Time (Prepared in Conjunction with Vendors)}

The major tasks required to be completed for finishing the gate area at Newark Airport has been determined with the help of vendors and Eco-Jet operations personnel.

\begin{tabular}{|c|l|l|l|l|l|c|}
\hline $\begin{array}{c}\text { Task } \\
\text { ID }\end{array}$ & \multicolumn{1}{|c|}{ Description of Tasks } & $\begin{array}{c}\text { Immediate } \\
\text { Predecessors }\end{array}$ & \multicolumn{1}{|c|}{$\mathbf{a}$} & $\mathbf{m}$ & $\mathbf{b}$ & $\begin{array}{c}\text { Responsible } \\
\text { Party }\end{array}$ \\
\hline A & Award Contract to Vendor & & 2 & 2 & 4 & Eco-Jet \\
\hline B & Finalize Telecom Wiring Plan & & 2 & 3 & 5 & Eco-Jet \\
\hline C & Finalize Electrical \& Plumbing Plan & & 1 & 2 & 3 & Eco-Jet \\
\hline D & Prepare (Rough) floors and walls & A & 12 & 16 & 20 & Vendor \\
\hline E & Acquire all furniture and fixtures & A, B, C & 2 & 2 & 2 & Eco-Jet \\
\hline F & Install telecom wiring as planned & B, D & 11 & 14 & 19 & Vendor \\
\hline G & Install electrical wiring as planned & C, D & 8 & 10 & 12 & Vendor \\
\hline H & Install rough plumbing as planned & C, D & 3 & 4 & 6 & Vendor \\
\hline I & Finish walls & E, F, G, H & 7 & 7 & 7 & Vendor \\
\hline J & Finish Floors & D & 3 & 3 & 3 & Vendor \\
\hline K & Install furniture and counters & F, G, J & 12 & 14 & 18 & Vendor \\
\hline L & Install telecom and network jacks & K & 3 & 4 & 5 & Vendor \\
\hline M & Finish plumbing work & I & 2 & 2 & 2 & Vendor \\
\hline N & Finish Electrical work & I, K & 3 & 3 & 3 & Vendor \\
\hline O & Test all computers & L, N & 1 & 2 & 5 & Eco-Jet \\
\hline P & Test phones, announcements etc. & L, N & 2 & 3 & 4 & Eco-Jet \\
\hline Q & Inspect entire premises & M, O, P & 1 & 1 & 1 & Eco-Jet \\
\hline R & Project Completion \& Sign-off & Q & 1 & 1 & 1 & Eco-Jet \\
\hline
\end{tabular}

\section{$\underline{\text { Notes }}$}

1. ' $\quad \mathrm{a}$ ' represents the optimistic time in days to perform a task.

2. ' $\mathrm{m}$ ' represents the most likely time in days to perform a task.

3. ' $b$ ' represents the pessimistic time in days to perform a task.

4. The time estimates remain the same for all three vendors.

It is important to note that in real life situation, a significant amount of effort is required in collecting the data by examining various documents and interviewing different people, developing assumptions to simplify the analysis, and presenting the data in an understandable form. 


\section{APPENDIX 4 - FLIGHT DELAY DATA}

Flight Delay Statistics (Prepared by Flight Operations)

\begin{tabular}{|c|c||c|c||c|c|}
\hline $\begin{array}{c}\text { Sample } \\
\text { Number }\end{array}$ & $\begin{array}{c}\text { Delayed } \\
\text { Flights }\end{array}$ & $\begin{array}{c}\text { Sample } \\
\text { Number }\end{array}$ & $\begin{array}{c}\text { Delayed } \\
\text { Flights }\end{array}$ & $\begin{array}{c}\text { Sample } \\
\text { Number }\end{array}$ & $\begin{array}{c}\text { Delayed } \\
\text { Flights }\end{array}$ \\
\hline 1 & 1 & 11 & 5 & 21 & 2 \\
\hline 2 & 2 & 12 & 4 & 22 & 2 \\
\hline 3 & 7 & 13 & 7 & 23 & 1 \\
\hline 4 & 2 & 14 & 3 & 24 & 0 \\
\hline 5 & 0 & 15 & 0 & 25 & 6 \\
\hline 6 & 1 & 16 & 1 & 26 & 4 \\
\hline 7 & 0 & 17 & 2 & 27 & 2 \\
\hline 8 & 1 & 18 & 0 & 28 & 1 \\
\hline 9 & 1 & 19 & 1 & 29 & \\
\hline 10 & 4 & 20 & 3 & 30 & 1 \\
\hline
\end{tabular}

\section{$\underline{\text { Notes }}$}

1. A random sample of 50 flights was taken over a 30 day period.

2. A flight more than 20 minutes late is classified as a delayed flight.

3. The airline industry's lower and upper (3-sigma) control limits for delayed flights are $2 \%$ to $15 \%$.

4. The average of delayed flights for the industry is $8.5 \%$.

It is important to note that in real life situation, a significant amount of effort is required in collecting the data by examining various documents and interviewing different people, developing assumptions to simplify the analysis, and presenting the data in an understandable form 